\title{
Plant-Based Milks: Almond ${ }^{1}$
}

\author{
Elena Torna, Daniela Rivero Mendoza, and Wendy J. Dahl²
}

Almond milk, a plant-based milk alternative, is produced from almonds and water (Dhakal et al. 2014). Almond milk originated from the Mediterranean region and has been consumed for many years. In the United States, there are several marketed brands of almond milk (Sethi et al. 2016). This publication describes the nutrient profile and potential health benefits and risks of almond milk.

\section{How is almond milk made?}

Commercial brands of almond milk are made from filtered water and almonds, vitamin and mineral blends, salt, and food additives, such as gums, ascorbic acid, sunflower lecithin, among others (Silk n.d., Blue Diamond Almonds n.d.). Sweeteners and flavors may also be added.

Production of almond milk starts with heating almond powder in water at $90^{\circ} \mathrm{C}$ (Sethi et al. 2016). Large particles are removed by centrifugation - a method of spinning. Homogenizing the almond fluid results in a uniform texture and appearance, similar to that of cow's milk (Sethi et al. 2016)Microorganisms are eliminated by treating the almond milk at ultra-high temperature (UHT) to produce a shelf-stable product (Sethi et al. 2016). Alternatively, almond milk may be pasteurized, which results in a product with a short shelf life needing refrigeration (Sethi et al. 2016). The high temperatures used for food safety purposes may result in nutrient losses (Sethi et al. 2016).

\section{How does the nutrient profile of almond milk compare to cow's milk?}

Plant-based milks vary in nutrient content. Almonds are nutrient-dense, providing essential fatty acids, vitamins, fiber, and phytochemicals (USDA n.d.). Minerals, such as calcium, potassium, phosphorus, magnesium, copper, zinc, and selenium, are also found in almonds (USDA n.d.). Almonds are also a source of vitamin E. However, almond milk contains very few almonds per serving; thus, the levels of these nutrients provided are lower than those in a serving of almonds. Fortification helps to ensure adequate intakes of essential vitamins and minerals. Almond milk may be fortified with calcium, as well as vitamins A and D.

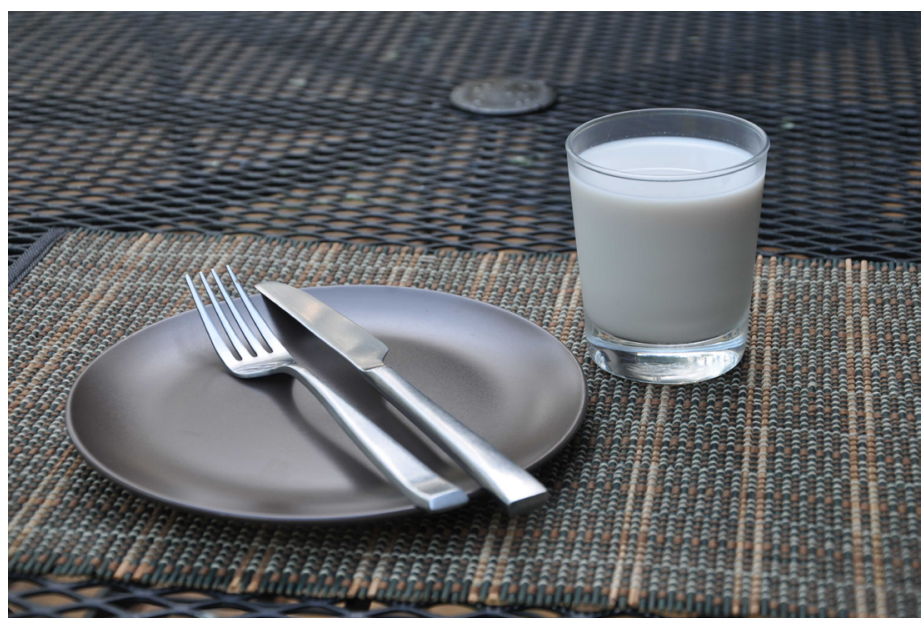

Credits: Lincoln Zotarelli, UF/IFAS

1. This document is FSHN20-48, one of a series of the Food Science and Human Nutrition Department, UF/IFAS Extension. Original publication date October 2020. Visit the EDIS website at https://edis.ifas.ufl.edu for the currently supported version of this publication.

2. Elena Torna, graduate student, Food Science and Human Nutrition Department; Daniela Rivero Mendoza, Extension and research coordinator; and Wendy J. Dahl, associate professor, Food Science and Human Nutrition Department; UF/IFAS Extension, Gainesville, FL 32611.

The Institute of Food and Agricultural Sciences (IFAS) is an Equal Opportunity Institution authorized to provide research, educational information and other services

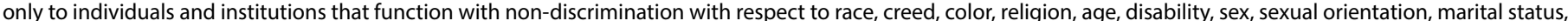
national origin, political opinions or affiliations. For more information on obtaining other UF/IFAS Extension publications, contact your county's UF/IFAS Extension office. U.S. Department of Agriculture, UF/IFAS Extension Service, University of Florida, IFAS, Florida A \& M University Cooperative Extension Program, and Boards of County Commissioners Cooperating. Nick T. Place, dean for UF/IFAS Extension. 
Table 1 summarizes the differences in the nutrient profiles of fortified, unsweetened almond milk and cow's milk; however, the nutrient profiles of unfortified, sweetened, flavored almond milks differ. A serving size of unsweetened almond milk ( 1 cup) contains about 30 calories, significantly fewer than the calories in cow's milk. However, a serving size of almond milk has only about $1 \mathrm{~g}$ of protein, whereas cow's milk contains $8 \mathrm{~g}$. A serving of almond milk has only $2.5 \mathrm{~g}$ of fat, similar to the amount in low-fat cow's milk. Almond milk contains no saturated fats, nor does skim fat-free cow's milk. Whole milk, on the other hand, has 8 grams of fat, of which about 5 grams are saturated fat. Almond milk is not a source of dietary fiber.

\section{What are the potential health benefits of almond milk?}

Almond milk may be a good option for adults who are allergic to cow's milk protein or for those who have lactose intolerance. Lactose is the sugar in cow's milk. Lactose intolerance is caused by an insufficiency of lactase, an enzyme that digests lactose. Almond milk does not contain lactose and therefore will not cause symptoms in people with lactose maldigestion (NLM n.d.). However, lactosefree dairy milks are also available in the market and may be appropriate for individuals trying to avoid lactose but wanting to get the nutritional benefits of cow's milk.

Almond milk may also be an appropriate substitute for cow's milk for vegans and vegetarian adults. However, it should be noted that the nutrient profile of almond milk is quite different from that of cow's milk, providing significantly less protein while still providing certain vitamins and calcium due to fortification. Finally, almond milk contains no saturated fat, which may be appealing for individuals who are trying to restrict their saturated fat consumption. Unsweetened, unflavored almond milk is typically lowcalorie, which may be appropriate for adults trying to lose weight.

\section{What are the possible risks of consuming almond milk?}

In some populations, such as older adults, replacement of cow's milk with a plant-based milk alternative may lead to an inadequate intake of protein. Tree nuts, including almonds, are one of the most common causes of allergic reactions, sometimes found to be fatal (McWilliam et al. 2015). Almonds contain a total of 188 proteins and amandin, or almond major protein (AMP), is amongst those. Amandin is not denatured after heat treatment and remains intact, making almond milk inappropriate for consumption by people with tree nut allergies. Almond milk is labeled as an allergen-containing food product, as required by the Food Allergen Labeling and Consumer Protection Act (FALCPA) (FDA) n.d.).

\section{Is almond milk an appropriate choice for children?}

Similar to other plant-based milks, the nutrient content of almond milk is not equivalent to cow's milk. Almond milk may be fortified with vitamins and calcium, which are essential for bone and tooth development in children and adolescents (ODS n.d.). However, almond milk provides very little protein for child growth (Silk n.d.). Plant-based milks with much less protein than cow's milk should not be used as a replacement for dairy (Sethi et al. 2016). Children older than 2 years old who cannot consume cow's milk are encouraged to drink fortified plant-based milk alternatives that have at least 6 grams of protein per serving, such as soy milk (Sethi et al. 2016). Almond milk should not be fed to infants. Infants require human milk, and in the absence of human milk, an appropriate infant formula.

\section{Summary}

Almond milk is a popular milk alternative. If unsweetened, it provides significantly less calories per serving than cow's milk, as well as no saturated fat, which makes it useful for those restricting calories or fat. If fortified, almond milk provides similar levels of calcium and vitamins A and $\mathrm{D}$ as cow's milk and may be appropriate for the diets of vegans and those with milk protein or soy allergy. However, consumers should be aware that, unlike cow's milk, almond milk contains very little protein, making it inappropriate as a dairy replacement for children.

\section{References}

Blue Diamond Almonds. n.d. "Unsweetened Original Almond Milk." Accessed September 1, 2020. https://www. bluediamond.com/brand/almond-breeze/almondmilk/ unsweetened-original

Dhakal, Santosh, Changqi Liu, Ying Zhang, Kenneth H. Roux, Shridhar K. Sathe, and V. M. Balasubramaniam. 2014. "Effect of High Pressure Processing on the Immunoreactivity of Almond Milk." Food Research International 62:2159-222. https://doi.org/10.1016/j.foodres.2014.02.021

McWilliam, Vicki, Jennifer Koplin, Caroline Lodge, Mimi Tang, Shyamali Dharmage, and Katrina Allen. 2015. “The 
Prevalence of Tree Nut Allergy: A Systematic Review." Current Allergy and Asthma Reports 15 (9): 54. https://doi. org/10.1007/s11882-015-0555-8

National Institute of Health Office of Dietary Supplements (ODS). n.d. "Calcium Fact Sheet for Health Professionals." Accessed September 1, 2020. https://ods.od.nih.gov/ factsheets/Calcium-HealthProfessional/

Sethi, Swati, Sanjeev K. Tyagi, and Rahul K. Anurag. 2016. "Plant-Based Milk Alternatives an Emerging Segment of Functional Beverages: A Review." Journal of Food Science and Technology 53 (9): 3408-3423. https://doi.org/10.1007/ s13197-016-2328-3

Silk. n.d. "Unsweet Almond Milk." Accessed September 1, 2020. https://silk.com/plant-based-products/almondmilk/ unsweet-almondmilk/
United States Department of Agriculture (USDA). n.d. "FoodData Central." Accessed September 1, 2020. https:// fdc.nal.usda.gov/index.html

United States Food and Drug Administration (FDA). n.d. "Food Allergies: What You Need to Know." Accessed September 1, 2020. https://www.fda.gov/Food/ResourcesForYou/Consumers/ucm079311.htm

United States National Library of Medicine (NLM): Genetics Home Reference. n.d. "Lactose Intolerance." Accessed September 1, 2020. https://ghr.nlm.nih.gov/condition/ lactose-intolerance\#statistics

Table 1. Nutrient profile of almond milk compared to fat-free, low-fat and whole cow's milk.

\begin{tabular}{|l|c|c|c|c|}
\hline & $\begin{array}{c}\text { Unsweetened almond milk } \\
\text { (1 cup) }\end{array}$ & $\begin{array}{c}\text { Fat-free skim milk } \\
\text { (1 cup) }\end{array}$ & $\begin{array}{c}\text { Low-fat (1\%) milk } \\
\text { (1 cup) }\end{array}$ & $\begin{array}{c}\text { Whole milk } \\
\text { (1 cup) }\end{array}$ \\
\hline Energy (Calories) & 30 & 83 & 102 & 150 \\
\hline Protein (g) & 1 & 8 & 8 & 8 \\
\hline Total fat (g) & 2.5 & 0 & 2.4 & 8 \\
\hline Saturated fat (g) & 0 & 0.1 & 1.5 & 4.5 \\
\hline Carbohydrate (g) & 1 & 12 & 12 & 12 \\
\hline Fiber (g) & $<1$ & 0 & 0 & 0 \\
\hline Total sugars (g) & 0 & 12 & 12 & 12 \\
\hline Vitamin A (mcg) & 150 & 149 & 142 & 112 \\
\hline Vitamin B12 (mcg) & NR & 1 & 1 & 1 \\
\hline Vitamin D (mcg) & 2.5 & 3 & 3 & 3 \\
\hline Calcium (mcg) & 450 & 298 & 305 & 276 \\
\hline Sodium (mg) & 125 & 102 & 107 & 105 \\
\hline Potassium (mg) & 170 & 381 & 366 & 322 \\
\hline NR Not reported; Source: (Silk n.d., USDA n.d.) & & & & \\
\hline
\end{tabular}

